\title{
Adapting Technology Acceptance Model to Predict Attitudes Toward Using E-Management Exploratory study of the views of the heads of the scientific departments at the University of Duhok
}

\author{
${ }^{1}$ Hadi Kh. Ismael, ${ }^{2}$ Saad F. Abbas
}

${ }^{1}$ Duhok Administrative Technical institute , Duhok Polytechnic University, Kurdistan Region, Iraq ${ }^{2}$ College of Administration and Economics, University of Duhok, Kurdistan Region, Iraq

\begin{abstract}
This study aimed to present the concept of (TAM) and e-management, and use the two constructsof TAM (perceived ease of use and perceived usefulness) as perceptual determinants for attitudes toward using emanagement at the University of Duhok.

The study adopted the descriptive approach, and utilized the questionnaire for data collection.

The study society consisted of all Heads of scientific departments at the university during the academic year 2016/2017 ( $N=52)$. The questionnaire was distributed to all members of the study society, and the response rate was $(100 \%)$. A numerous of statistical methods were used to analyze the data and test the hypotheses which provided for the existence of significant correlation and impact between both perceived ease of use and perceived usefulness and the attitudes towards using e-management.

The results of study showed that most of the respondents held a positive attitude towards using emanagement. The results also showed that there is a statistically significant impact of both perceived ease of use and perceived usefulness on the attitudes towards using e-management, with moral significance at $(\mathrm{P} \leq 0.01)$. The study presented a set of suggestions among them developing training programs that raise the level of perceived ease of use and perceived usefulness of e-management among administrative leaders in the university, and qualify them to deal with the use of e-management.

Keywords: Technology acceptance model, Perceived ease of use, perceived usefulness, e-management, emanagement functions.
\end{abstract}

\section{Introduction}

The third millennium is nominated by scholars as the era of knowledge and information technology (IT); the need to use paper decreased somewhat, managers became exercised their activities at any time and in any place more efficiently than in the past, managerial functions face many and multi challenges, where the most Important challenges are the technological changes that came by the various components of

Academic Journal of Nawroz University

(AJNU) Volume 8, No 4 (2019).

Regular research paper : Published 30 Dec 2019

Corresponding author's e-mail : hadi.kh@gmail.com

Copyright (C2018 ${ }^{1}$ Hadi Kh. Ismael, 2Saad F. Abbas.

This is an open access article distributed under the Creative

Commons Attribution License. information technology, especially the internet, extranet, increasing in computer use, and development of administrative thought and business networks in the completion of the managerial functions (planning, organizing, directing, and controlling) electronically.

E-management is the latest approaches in the management school that seek to convert the Institutions to electronic institutions using information technology in the delivery of all its functional and transactions; therefore, most organization, including universities, have sought to implement e-management, in order to benefit from the advantages of electronic means to convert managerial functions from a paper nature into 
an electronic nature.

The success of using e-management depends to a large extent on the attitudinal beliefs of the administrative leaders towards the importance of using emanagement. In this regard, many attitudinal beliefs of the administrative leaders at the university such as perceived ease of use and perceived usefulness do prevent the effective using of e-management at the university.

Based on the above, the present study will use the constructs of TAM (perceived ease of use and perceived usefulness) to reveal the perceptual determinants for attitudes towards using e-management at university of Duhok.

\section{Methodology}

\subsection{Problem and questions of the study}

The contemporary organizations, including universities, need to use e-management in order to benefit from electronic means by reducing the paperwork and the completion of managerial functions (planning, organizing, leading and control) electronically .Many scholars confirm that the success of using electronic means in the administrative work and the shift from paperwork to electronic work depends to a certain extent on the nature of the administrative leader's attitudes towards using electronic means, in the extent of being positive or negative(Lai, 2017:21-38; Masrom,2007:10;Alrahahle ,2014:264-271).

Based on the above, the problem of the study can be formulated in the following questions:

A. What is the nature of the attitudes held by the heads of scientific departments at the university of Duhok towards using e-management?

B. What is the level of perceived ease of use and perceived usefulness among heads of scientific departments in the University of Duhok?
C. Is there a significant relation between each of perceived ease of use and perceived usefulness, and the attitudes towards using e-management?

D. Does perceived ease of use and perceived usefulness impact significantly on the attitudes towards using e-management?

\subsection{The importance of the study}

This study is important in that it contributes to enriching the literature of management by addressing two important topics, namely TAM and e-management. The importance of this study comes also through it is being considered as one of the very few researches that examined the relationship between perceived ease of use , perceived usefulness, and the attitudes towards using e-management in the context of Duhok university, therefore, the results of this study is expected to encourage Administrative Leading in the university to increase the level of using e-management, and diagnosis the conceptual determinates among them which may impact the success of effective using of e- management.

\subsection{Objectives of the study}

A. Measuring the level of perceived ease of use and Perceived usefulness among heads of

A. Scientific departments towards using emanagement the university of Duhok.

B. Diagnosing the nature of the attitudes held by heads of scientific departments at the University of Duhok towards using e- management.

C. Identify the impact of both perceived ease of use and perceived usefulness on the attitudes towards using e-management.

D. Providing a set of suggestions to facilitation using e-management at university of Duhok.

\subsection{The model and hypotheses of the study}

Figure (1) shows the proposed model of the study, which is developed based on the theoretical and 
conceptual framework. The proposed model contains Three main variables: The first is perceived ease of use, the second is perceived usefulness, and the third is attitudes towards e-management.

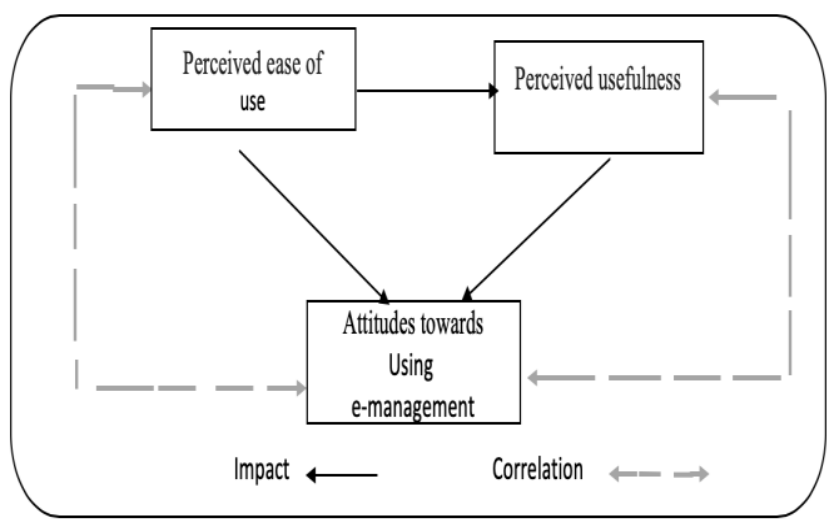

Figure (1): The proposed model of the study

The following hypotheses emerged from the proposed model of the study:

$\mathrm{H}_{1}$ : There is statistically significant relation at $(a \leq 0.05)$ between perceived ease of use and perceived usefulness.

H2: perceived ease of use has a significant impact at ( $a \leq$ 0.05) on perceived usefulness.

H3: There is statistically significant relation at $(a \leq 0.05)$ between perceived ease of use and attitudes towards using e-management.

H4: Perceived ease of use has a significant impact at ( $a \leq$ 0.05) on attitudes towards using e-management.

$\mathrm{H} 5$ : There is statistically significant relation $a t(a \leq 0.05)$ between perceived usefulness and attitudes towards emanagement.

H6: Perceived usefulness has a significant impact at ( $a \leq$ 0.05) on attitudes towards using e-management.

\subsection{Data collection instrument}

Primary data for this study were collected from respondents using a questionnaire consists of four basic parts are as follows: First Part looked at the demographic characteristics of respondents; the second part was devoted to measuring perceived ease of use , the third part was devoted to measuring perceived usefulness, while the forth part was devoted to measuring attitudes towards using e-management.

Perceived ease of use and perceived usefulness were assessed using (Davis et al. ,1989) standard questionnaire which consist of (5) items for each variable. Attitudes towards using e-management was assessed using (Abu-Ashour and Nimry,2013) standard questionnaire which consist of (24) items.

Respondents in this study rated each item on a 5-point Likert scale ranging from strongly disagree (1) to strongly agree (5).

In order to ascertain the ability of the questionnaire to measure the variables of the study, Reliability of the questionnaire was measured using Cronbach's alpha coefficient,

The values of Cronbach's alpha were $(0.87)$ at the total level of the scale, (0.85) for perceived ease of use, (0.94) for perceived usefulness and (0.82) for attitudes toward using e-management, thus, it can be concluded that the measures have an acceptable level of reliability.

The collected data have been analyzed by using various statistical techniques, such as Mean, Standard Deviations, Coefficient of Agreement, Person Correlation Coefficients, Regression Analysis.

\section{LITERATURE REVIEW}

\subsection{TAM: Concept and Constructs}

TAM is specific to predict information technology usage, by applying the concepts of perceived ease of use and perceived usefulness, it adopts the simplest assumptions when formulating or interpreting data, and helps to understand and explain user behavior (Lai and Zainal, 2015:1-13). TAM could be also useful in predicting end users acceptance of different technologies such as word processors, email, the world wide web. And could predicts information technology acceptance under different conditions, such as time and 
culture, with different control factors, and has been applied in different forms to explain technology adoption in a wide variety of contexts, ranging from individual to organizational technology acceptance (Olushola and Abiola, 2017:77).

TAM was introduced for the first time by Fred Davis in 1986 for his doctorate proposal based on the theory of reasoned Action (TRA) by Ajzen and Fishbein (1980), and theory of planned behavior (TPB) developed by Ajzen (1985) , and tailored to the context of technology acceptance and usage ,In 1989, Davis used TAM to explain computer usage behavior, and to find out what factors cause people to accept or reject an information technology (Masrom ,2007 :2).

The final version of TAM was formed by (Venkatesh and Davis, 1996:451-481)as shown in Figure (2) after the main finding of both perceived ease of use and perceived usefulness were found to have a direct impact on behavior intention, thus eliminating the need for the attitude construct.

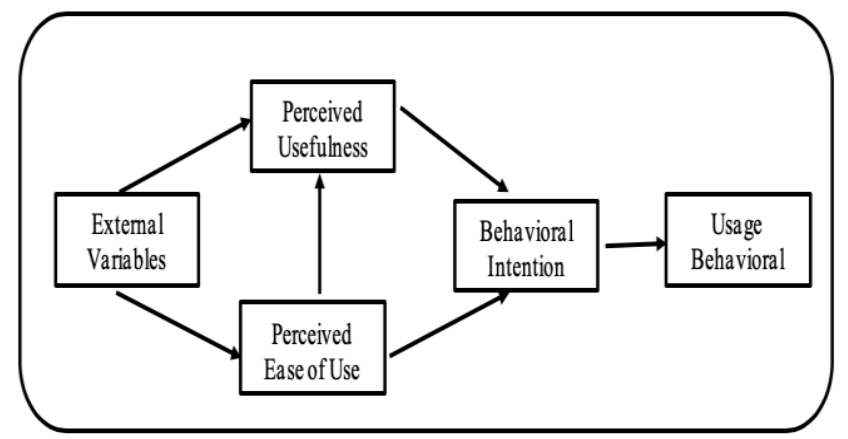

Figure (2) Final version of Technology Acceptance

\section{Model}

Source:Lai,P. C. (2017), The Literature Review Of Technology Adoption Models And Theories For The Novelty Technology, JISTEM - Journal of Information Systems and Technology Management Vol. 14, No. 1, Jan/Apr ,pp. 21-38 ISSN online: 1807-1775 DOI: 10.4301/S1807-17752017000100002

Perceived ease of use and Perceived usefulness are the main constructs of TAM, and these constructs determine user's attitude towards using technology, which in turn, impacts his behavioral intention to use technology (Olushola and Abiola, 2017:71).In TAM , perceived ease of use refers to how effortless he or she perceives using the technology will be, while perceived usefulness refers to the degree to which the user believes that using the technology will improve his or her performance (Lai, 2017:25. Both perceived ease of use and perceived usefulness are considered distinct factors influencing the user's attitude towards using the technology, though perceived ease of use is also hypothesized to impact perceived usefulness and attitude towards using the technology, and such attitude towards using the technology determines the behavioral intention to use that technology(King and He ,2007:740-755).

For the purpose of this study we define perceived ease of use as the degree to which the heads of scientific departments believes that using e-management at the university will be effortless, while we define perceived usefulness as the degree to which heads of scientific departments believes that using e-management will improve their performance.

\subsection{E-management: Concept and Functions}

E-management emerged following the wide spread use of computers in the 1950s and 1960s when organization srealized that using computers meant convenience and saving of time, effort and resources. It can be safely said that the emergence of electronic data sharing systems and networks represented the cradle for the birth of Emanagement, and the development of its new functions and roles through the use of modern networks, especially intranet and extranet, digital space, internet and technological infrastructure of IT(Ellatifand Sammani, 2013:2)

According to (Seresht et al., 2008:2) e-managementsis an 
administrative process that depends on the possibilities of the internet and business networks in the planning, direction and control of resources in order to achieve the organizational goals. Another definition indicates that the e-management is the use of information technology and communications to improve governance and management processes (Alrahahle, 2014:266).

In a definition that has been commonly used (Rawash, 2014:2014) definedthe e-management as a contemporary approach that seek to convert the institutions to electronic institutions, using information technology in the delivery of all its functional and transactions and managerial functions.

Regarding the e-management at the university, it has defined as the University's use of information and communication technology to carry out its activities through the transformation of electronic work to improve performance and administrative processes, achieve quality of services, and achieve university objectives with the least time, effort and cost. (AbuAshour, and Al-Nimry ,2013:200). Another definition describes it as the adopting of electronic means for achieving University's managerial function which include: planning, organization, supervision and decision making (Ghazi, et al., 2015:1).

In this study, we shall define the term e-management as the adoption of electronic means for achieving university managerial functions which includes: planning, organizing, leading and controlling of university activities.

Regarding the important of e-management, according to (Abu Ashour and AlNemri, 2013;199-220) the availability of e-management participates efficiently in achieving the goals and strategies of the organizations globalization and fulfilling the desires of the organization in order to continue and stay up to date, it alsohelps revealing the deviations sooner to prevent its aggravation and put the needed treatment. In the same time, (Khammas,2002:146-158) assured the importance of information management in the last three decades where it became the motive to enhance its presence in all commercial and services public institutions, due to the role it plays when applied, and this gave it extra advantages. (Batianech,2017:86-100) indicated the importance of the technical and scientific progress, and the continuous push to raise the quality of the outcomes and assure the safety of the procedures, where the time factor is the main competitive aspects between organizations and it is not accepted to delay the execution of operations, and that is because the opportunities are linked to the time element.

Regarding e-management functions, on the whole, scholars agreed on four functions of which are: eplanning, e-organizing, e-leading, and e-controlling.

E-planning means determining what is intended done instantly and in the future, depending on the flow of information from inside and outside the institution and cooperation joint between the top and bottom to benefit from the electronic network to meet the requirements of marketing changing and the needs of potential customers and their preferences (Mafraji, 2007:79).

E-organizing expresses the use of electronic means in determining the general framework for the distribution of power, tasks and network-horizontal relationships, and finding the necessary coordination in order to achieve organizational goals, (Najem,2004:250-251). E-leading is defined as a social impact process mediated by advanced information technology to produce a change in attitudes, feelings, thinking, behavior, and/or performance with individuals, groups, and/or organizations, electronic Leading takes place in a context were work is mediated by 
information technology (Jae , 2010: 11; Avolio et al., 2000: 615-668).

E-controlling is the process of using electronic methods to get the information that allow management to measuring and correcting the performance of assigned activities of subordinates in order to ensure that the goals of the organization and plans that are designed to reach them have already achieved (Rawash, 2014:218).

\section{RESULTS}

4.1. The Society of The Study and Demographic Profile The Society of the study consists of all heads of scientific departments in the University of Duhok during the academic year 2016/2017 ( $N=52)$. There were 52 sets of questionnaires, $(100 \%)$ were returned and were properly completed and eventually collated for the study. Tables (1) below shows the profile of the respondents.

Table (1): Demographic profile

\begin{tabular}{|c|c|c|c|}
\hline Variables & Descriptions & Freq. & $\%$ \\
\hline \multirow{2}{*}{ Gender } & Male & 48 & 92 \\
\cline { 2 - 4 } Age & Female & 4 & 8 \\
\hline \multirow{2}{*}{$\begin{array}{c}\text { Below 30 years } \\
\text { Academic } \\
\text { qualification }\end{array}$} & Above 45 years & 21 & 2 \\
\cline { 2 - 4 } & Master & 8 & 58 \\
\hline $\begin{array}{c}\text { number of years' } \\
\text { respondents have } \\
\text { been working as } \\
\text { head of } \\
\text { department }\end{array}$ & Below 3 years & 44 & 85 \\
\cline { 2 - 4 } & 3-7 years & 17 & 33 \\
\hline \multirow{2}{*}{$\begin{array}{c}\text { above 7 years } \\
\text { Scientific title }\end{array}$} & $\begin{array}{c}\text { Lecturer } \\
\text { Prsistant }\end{array}$ & 13 & 25 \\
\cline { 2 - 4 } & $\begin{array}{c}\text { Professor } \\
\text { Profsor }\end{array}$ & 34 & 65 \\
\cline { 2 - 4 } & 4 & 8 \\
\hline
\end{tabular}

Source: Results of SPSS

The results show that percentage $(92 \%)$ of respondents are males and $(8 \%)$ are females. Their age is categorized into 3 groups with (2\%) aged in the range of below 30 years old, (40\%) aged in the range above 30 - 45 years old and (58\%) aged more than 45 years old. Regarding the academic qualification; majority of them were Doctoral holders that constitute $(85 \%)$, the remaining respondents $(15 \%)$ were master holders . Pertaining to number of years' respondents have been working as head of department; $(42.5 \%)$ of them had been working with this position below (3) years, (33\%) had been working for (3-7) years, the remaining respondents (25\%) had more than 7 years of working as head of department. Regarding the scientific title; $(65 \%)$ of them were assistant professor, $(27 \%)$ were lecture, and the remaining respondents $(8 \%)$ were professor

\subsection{Descriptive Statistics}

To determine the levels of the basic variables of the study; Mean values (M) were calculated, Standard deviation (SD) used for measuring the dispersion of a set of data from its Mean, whereas Coefficient of agreement (CA) used for ranking. The results were as follows:

\begin{tabular}{|l|l|l|l|l|l|}
\hline No. & Items & $\mathrm{M}$ & SD & CA\% & Degree \\
\hline 1 & $\begin{array}{l}\text { perceived ease } \\
\text { of use }\end{array}$ & 4.27 & $\begin{array}{l}0.5 \\
0\end{array}$ & 88 & High \\
\hline 2 & $\begin{array}{l}\text { perceived } \\
\text { usefulness }\end{array}$ & 4.19 & $\begin{array}{l}0.5 \\
9\end{array}$ & 86 & High \\
\hline
\end{tabular}

\section{A. Perceived ease and perceived usefulness}

To determine the degree of perceived ease of use and perceived usefulness, Mean values were categorized into three degrees that are: Mean value of (1-2.33) indicates low level, Mean values of (2.34 -3.67) indicates medium level, and the Mean values of (3.68-5) indicates a high level.Table (2) shows the results as follows:

\section{Table (2): Descriptive statistics of perceived ease of} use and perceived usefulness

Source: Results of SPSS

- The majority of the respondents agree that perceived ease of use, is practiced at high level in the surveyed 
hotels (mean $=4.27$, Standard Deviation $=0.50$ coefficient of agreement $=88 \%$ ).

- The majority of the respondents agree that perceived usefulness, is practiced at high level in the surveyed hotels $($ mean $=4.19$, Standard Deviation $=0.59$ coefficient of agreement $=86 \%$ ).

\section{B. Attitudes toward using e-management}

To determine the nature of the attitudes toward emanagement, Mean values were categorized into three degrees that are: negative (Mean values of 1-2.33), neutral (Mean values of 2.34 - 3.67), and positive (Mean values of 3.68-5). Table (3) show the results as follows the results were as follows:

- The majority of the respondents agree that they have positive attitudes toward using e-management as a whole and toward the four functions of the emanagement (e-planning, e-organizing, e-leading, and e-control) in the University of Duhok (mean $=3.93$, Standard Deviation $=0.68$ coefficient of agreement $=83 \%)$.

- The attitudes towards e-organizing ranked first in terms of in terms of their degree of positivity among attitudes towards the functions of e-management $($ Mean $=4.05$, Std. Deviation $=0.54$, coefficient of agreement $=87 \%$ ), while in the last rank came attitudes towards e-controlling $($ Mean $=3.68$, Std. Deviation $=$ 0.92 , coefficient of agreement $=75 \%$ ).

Table (3): Descriptive statistics of attitudes toward using e-management

\begin{tabular}{|l|l|l|l|l|l|}
\hline No. & Items & $\mathrm{M}$ & $\mathrm{SD}$ & $\mathrm{CA} \%$ & $\begin{array}{l}\text { Nature of } \\
\text { attitudes }\end{array}$ \\
\hline 1 & E- management & 3.93 & 0.68 & 83 & Positive \\
\hline 2 & E- planning & 4.04 & 0.61 & 85 & Positive \\
\hline 3 & E- organizing & 4.05 & 0.54 & 87 & Positive \\
\hline 4 & E- leading & 3.94 & 0.66 & 83 & Positive \\
\hline 5 & E- controlling & 3.68 & 0.92 & 75 & Positive \\
\hline
\end{tabular}

Source: Results of SPSS

\subsection{Hypotheses Testing}

\section{A. First hypothesis (H1)}

Spearman correlation coefficient was used as the study is intended to test the first hypothesis of the study (H1), and the results of the Correlation analysis presented in table (4). The results reveal that the Perceived ease of use is highly correlated with perceived usefulness $(R=0.49, p<0.01)$, therefore the first hypothesis was accepted.

\section{B. Second hypothesis (H2)}

In testing Hypothesis (H2), a regression analysis was performed, with perceived ease of use as an independent variable and perceived usefulness as the dependent variable. Table 4 presents the regression results. As indicated in Table(4), perceived ease of use had a significant impact on perceived usefulness $(\beta=$ $0.49 ; \mathrm{p}<0.01)$. According the results $(24 \%)$ of the variance in the values of perceived usefulness is explained by perceived ease of use $\left(R^{2}=0.24\right)$, and the rest of the percentage $(76 \%)$ is explained by other variables. The regression model is significant $(F=15.57$, $\mathrm{p}=0.01)$. Thus, Hypothesis (H2) was supported

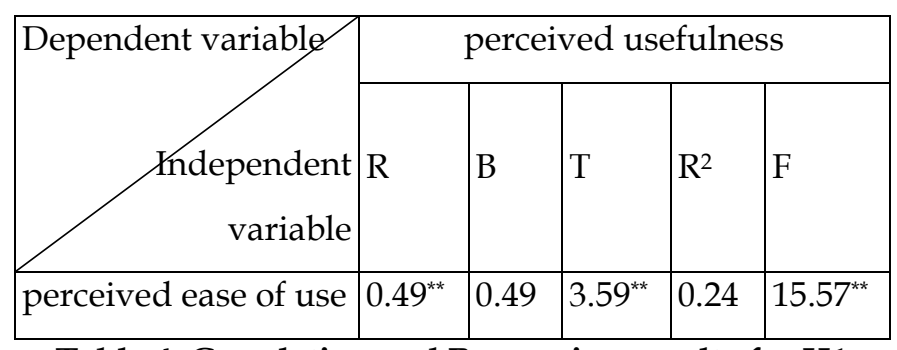

Table 4. Correlation and Regression results for $\mathrm{H1}$ and $\mathrm{H} 2$

${ }^{*}$ Significant at the 0.01 level (2-tailed)

Source: Results of SPSS

\section{Third hypothesis (H3)}

Spearman correlation coefficient was used as the study is intended to test the third hypothesis of the study 
(H3), and Table (5) presents the value of Spearman correlation coefficient between perceived ease of use and attitude toward using e-management. The results showed significant relation between these two variables $(\mathrm{R}=0.48, \mathrm{p}<0.01)$, therefore the third hypothesis $(\mathrm{H} 3)$ was accepted.

\section{Forth hypothesis (H4)}

For the purpose of testing the Forth hypothesis of the study (H4), a simple regression analyses was carried out to find out the extent to which perceived ease of use explained attitudes toward using e-management, and table (5) demonstrates the results. The simple regression analysis between these two variables according to the results $(\beta=.23, \mathrm{~T}=3.88, \mathrm{p}<0.00)$ indicated that there is a statistically significant impact of perceived ease of use onE-management. According to the results $(23 \%)$ of the variance in the values of attitudes toward using e-management is explained by ease of use $\left(R^{2}=0.23\right)$, and the rest of the percentage $(77 \%)$ is explained by other variables. The regression model is significant $(\mathrm{F}=15.1, \mathrm{p}=0.01)$, therefore, Hypothesis (H4) was supported

Table 5. Correlation and Regression results for $\mathrm{H3}$ and $\mathrm{H} 4$

\begin{tabular}{|c|c|c|c|c|c|}
\hline \multirow{2}{*}{ Independent } & \multicolumn{5}{|c|}{$\begin{array}{l}\text { Attitude toward e- } \\
\text { management }\end{array}$} \\
\hline & $\mathrm{R}$ & B & $\mathrm{T}$ & $\mathrm{R}^{2}$ & $F$ \\
\hline perceived ease of use & $0.48^{* *}$ & 0.23 & $3.88^{* *}$ & 0.23 & $15.1^{* *}$ \\
\hline
\end{tabular}

* Significant at the 0.01 level (2-tailed)

Source: Results of SPSS

\section{E. Fifth hypothesis (H5)}

As the study is intended to test the relation between perceived usefulness and attitude toward using emanagement, the value of Spearman correlation coefficient was calculated. The results of processing data questionnaire relating to the two variables presented at table (6), and showed a strong significant relation between these two variables $(R=0.72, p<0.01)$, therefore the Fifth hypothesis (H5) was accepted.

\section{F. Sixth hypothesis (H6)}

Looking at the impact of perceived usefulness on attitude toward using e-management, a simple regression analysis was performed, and table (6) shows the results. The results indicate that there is a statistically significant impact of perceived usefulness on attitude toward using e-management $(\beta 0.72, T=7.39$, $\mathrm{p}<0.01)$.In addition to that $(52 \%)$ of the variance in the values of attitudes toward using e-management is explained by perceived usefulness $\left(R^{2}=0.52\right)$, and the rest of the percentage (48\%) is explained by other variables. The regression model is significant $(F=54.5$, $\mathrm{p}=0.01)$.

Table (6): Correlation and Regression results for $\mathrm{H} 5$ and $\mathrm{H} 6$

\begin{tabular}{|c|c|c|c|c|c|}
\hline \multirow{2}{*}{ Dependent variable } & \multicolumn{5}{|c|}{$\begin{array}{l}\text { Attitude } \\
\text { management }\end{array}$} \\
\hline & $\mathrm{R}$ & B & $\mathrm{T}$ & $\mathrm{R}^{2}$ & $\mathrm{~F}$ \\
\hline perceived usefulness & $0.72^{* *}$ & 0.72 & $7.39^{* *}$ & 0.52 & $54.5^{* *}$ \\
\hline
\end{tabular}

*Significant at the 0.01 level (2-tailed

Source: Results of SPSS

\section{DISCUSSION}

This study examined the utility of TAM for explaining acceptance of e-management by heads of scientific departments. The results of descriptive statistics showed high levels of perceived ease of use, which reflects high degree of believes among heads of scientific departments at the university of Duhok that implementing e-management in the university will be effortless.

The results of descriptive statistics showed also high level of perceived usefulness, which indicate that heads 
of scientific departments at the university of Duhok belief at high degree that using e-management, will improve their performance of managerial functions.

Based on the results of the correlation analysis between main variables of the study, that have been shown to be significant and positive, Accordingly, the following can be noted :

A. The high level of perceived usefulness is associated with the high level of perceived usefulness, and vice versa.

B. Positive attitude toward using e-management is associated with the high level of perceived ease of use, while negative attitude toward using emanagement is associated with the low level of ease of use.

C. Positive attitude toward using e-management is associated with the high level of perceived usefulness, while negative attitude toward using emanagement is associated with the low level of usefulness.

Based on the results of the regression, Perceived ease of use has a significant impact on perceived usefulness. This result indicate that perceived ease of use is an conceptual determinate of usefulness, and support the view of many researches e.g.: (Davis et al, 1989: 9821003 ; King and He ,2007:740-755 ; Olushola and Abiola ,2017:73-83 ) whom suggests, that ease of use may be an antecedent of usefulness, rather than a parallel, direct determinant of usage.

The results of regression analysis indicated that both ease of use and usefulness impact significantly on attitudes toward using electronic management, this means ease of use and usefulness are perceptual determinants of attitude toward using e-management, and this results provide a clear message to the administrative leaders in the university, which is if they want to raise the level of using e-management at the university, they must focus on providing proper user training for directing and solidifying heads of scientific departments $s^{\prime}$ perception of the ease of use and usefulness of the electronic management. This result is consistent with the results of many past researches results which have provided evidence for the significant impact of both perceived ease of use and perceived usefulness on the attitudes toward using electronic means (Henderson, and Divett, 2003:383395;Masrom ,2007:1-10; Olushola and Abiola ,2017:7383)

According to the results $(23 \%)$ of the variance in the values of attitudes toward using e-management is explained by ease of use, while (52\%) of the variance is explained by usefulness. These results showed that perceived usefulness is more important in determining attitudes toward using e-management than perceived usefulness. An explanation might be that heads of scientific departments are willing to adopt beneficial applications of e-management, and this may suggest that they tend to focus on the usefulness of the emanagement itself.

However, there are a large percentage of attitudes toward using e-management that is explained by other factors out the study model. This can be explained by the fact that attitudes toward using e-management can be impacted by many situational factors such as age, gender, duration of service, level of education, social status, motivation to use, working conditions, flexible work arrangements, organizational culture, organizational structure, organizational climate, nature of communications, etc. This view is consistent with the view of (Seresht et al., 2008:1-8) who suggested additional factors to be included in the original TAM such as corporate culture, organizational environmental, and other managerial, humanistic, technological factors, which affect the attitudes toward 
using e-management, positively or negatively

\section{CONCLUSIONS AND SUGGESTIONS}

\subsection{Conclusions}

- There is a clear tendency among the respondents to agree on the existence of high degree of perceived ease of use, and this means strong believes among respondents that using electronic means will be effortless, and it is easy for them to deal with the modern technology.

- The majority of the respondents agreed on the existence of high degree of perceived usefulness, which means most of them beliefs that using emanagement will enhances their ability to perform their functions effectively.

- The findings indicated positive attitudes among respondents toward using e-management Functions (e-planning, e-organizing, e-leading, and e-control) at the University of Duhok, reflecting the presence of a clear tendency among them to adopt modern technology, and electronic means in managerial work to take advantage from its capabilities in developing the university.

- The findings indicate a positive significant correlation between ease of use and perceived usefulness, therefore, the university can increase the degree of perceived usefulness of using emanagement among administrative leaders when they increase the degree of perceived ease of use among them, through the provision of electronic means, and the removal of administrative and technical obstacles that have been transformed without their ability to use them.

- Based on the results of the hypotheses testing, perceived ease of use is one of the predictors of perceived usefulness, this means it is possible for the University of Duhok to determine the expected levels of perceived usefulness among heads of scientific departments based on the extent of which perceived ease of use they have.

- This study indicated that when the respondents have high degree of perceived ease of use and perceived usefulness, they will provide positive attitudes toward using e-management. From a managerial standpoint, these findings reveal that, in order to foster individual to use electronic management, positive perception of the emanagement's ease of use and usefulness is crucial.

- The impact of perceived usefulness on attitude toward using e-management was stronger than the perceived ease of use of it, this results highlight the importance of perceived usefulness as a perceptual determinate of attitude toward using emanagement.

- The results of the study showed that TAM can be used to reveal the perceptual determinants of attitude toward using e-management at the University.

\subsection{Suggestions}

- Supporting the infrastructure for implementing emanagement, and developing training programs that raise the competency of administrative leaders with a view to perceived ease of use and perceived usefulness, and qualify them to deal with using of electronic management

- Encouraging positive attitudes towards the use of e-management, and change negative attitudes through an effective incentive system, whereby financial and non-financial incentives are given to those who excel in using e-management, and overcome the resistance that some employees may have toward using of electronic management.

- Supporting the culture of using e-management in the daily work of the university, and clarify the possibilities that e-management can provided to 
administrative leaders, through regular and continuous seminars, holding required meetings, and workshops, in line with developments that occur on modern technology.

- Expand the use of e-forms to take the advantages of multiple benefits like reduce the expenditure and to reduce the time of work, and restructuring the organizational structures of the university in accordance with the process of change to the emanagement.

- Adopting e-management as a scientific course within the curricula of undergraduate and graduate studies, especially in the college of administration and Economics, and directing graduate students and teaching staff to adopt e-management as a research field.

- Expand the existing Internet network at the university and make it available to all university employees.

- Developing legislation, regulations and managerial procedures in line with electronic transactions imposed by the use of e-management. administration

\subsection{Limitations and Future Studies}

The main limitation of this study is related to its design. This study was based on the determination of the level of perceived ease of use, perceived usefulness, and attitudes toward using e-management from the point of view of supervisory management (heads of scientific departments) at the university of Duhok, therefore, further study could be conducted to determine these variables from the point of view of the top management and frontline management of the university.

As the sample size is small, the outcome of the study is not precisely accurate, thus there is a need to include another universities in future studies.

This study was conducted in high education sector, therefore the findings may be applicable to this particular sector, to expand the theoretical validity of the literature, reexamination of TAM with another sector or user population and different information technology (IT) application will be important, so that the findings can be generalized to a bigger population.

This study did not test a full TAM, as it consider only the impact of perceived ease of use and perceived usefulness on attitudes toward using e-management , future study could add some other variables that affect attitude toward using e-management such as, organization climate, organizational culture, prior usage, user experiences, and user characteristics.

\section{References}

\subsection{Thesis}

1. Jae Won, Jung (2010), The Role of Social Media in ELeading, Master's Thesis in Media Technology, Royal Institute of Technology, School of Computer Science and Communication, Stockholm, Sweden.

\subsection{Periodicals \& Journals}

1. Abu-Ashour, Khalifeh and Al-Nimry Deana, (2013)The Level of Applying Electronic Administration at Yarmouk University as Perceived by Administrators and Faculty Members, Jordanian Journal of Educational Sciences, Volume 9, Number 2, pp:199-220.

2. Alrahahle, Abdelrazaq Salem (2014), The Impact of E-Management and the Role of Human Resource Development in Improving the Performance of the Organization, International Journal of Business and Social Science Vol. 5, No. 10; September pp:264-271.

3. Avolio, B. J., Kahai, S., \& Dodge, G. E. (2000). Eleading: Implications for theory, research, and practice. The LeadingQuarterly , 11 (4), 615-668.

4. Bataineh ,Khaled Adnan ,(2017),The Impact of Emanagementon the Employees' Performance ,Field 
Study on the Public Organizations and Governance in Jerash

5. Governorate, Journal of Management and Strategy ,8(5),86-100).

6. Davis, F.D., Bagozzi, R.P., \&Warshaw, P.R. (1989). User acceptance of computer technology: a comparison of two theoretical models. Management Science, 35(8), 982-1003.

7. Ellatif ,HuthaifaAbdelkarim and Sammani , Abdulmutalib Ahmed (2013), E-Management: Configuration, Functions and Role in Improving Performance of Arab Institutions and Organization, International Journal of Computer Applications (0975 - 8887) Volume 80 - No.6, October.

8. Ghazi. I.; RahoMuzhir; Shaban Al-Ani; Khattab M. and Ali Al-Heeti, (2015), E- University Environment Based on Emanagement,International Journal of Computational Engineering Research (IJCER), Volume 5, Issue,

9. Henderson, R. \&Divett., M., J. (2003). Perceived usefulness, ease of use and electronic supermarket use. International Journal of Human-Computer Studies, 59, 383-395.

10. Khammas, G. S. (2002). Information Technology and Its Impact on the Etechnical Setting in the Elibraries. IraqiMagazine for Libraries And Information, 6(2), 146-158.

11. King, R. R. \& He, J. A Meta-Analysis of the Technology Acceptance Model.

12. Information \& Management. Vol. 43, 2007, 740-755.

13. Lai, P. C. (2017), The Literature Review Of Technology Adoption Models And Theories For The Novelty Technology, JISTEM - Journal of Information Systems and Technology Management Vol. 14, No. 1, Jan/Apr ,pp. 21-38 ISSN online: 1807-1775 DOI: 10.4301/S1807-17752017000100002.
14. Lai P. C. \&Zainal A. A., (2015). Consumers' Intention to Use a Single Platform EPaymentSystem: A StudyamongMalaysian Internet and Mobile Banking Users. Journal of Internet Banking and Commerce. (20) (1) 1-13.

15. Olushola Thomas and Abiola James O. (2017), the Efficacy of Technology Acceptance Model: A Review of Applicable Theoretical Models in Information Technology Researches, Journal of Research in Business and Management Volume 4, Issue 11 pp: 70-83, ISSN (Online): 23473002www.questjournals.org

16. Rawash Hassan N., (2014), Electronic Management's Contribution to the Development of Managerial Functions, Academic Research International Vol. 5(5) September, pp: 213-255, www.savap.org.pk 213 www.journals.savap.org.pk

17. Seresht, H. R., Fayyazi, M., \&Asl, N. S. (2008). Emanagement: Barriers and Challenges in Iran. EowerKraklead , 1-11.

18. Venkatesh, V., \& Davis, F. D. (1996). A model of the antecedents of perceived ease of use: Development and test. Decision Sciences, 27(3), 451-481.

\subsection{Conferences}

1. Masrom , Maslin(2007), Technology Acceptance Model and E-learning12th International Conference on Education, Sultan Hassan al Bolkiah Institute of Education University Brunei Darussalam ,21-24 May,https://www.researchgate.net/publication/2 $\underline{28851659}$

\subsection{Books}

1. Mafraji, A. H. (2007). E-governance "intellectual foundations and the establishment of requirements process". The Arab Organization for Administrative Development, Egypt.

2. Najem, N. A. (2004). E-management (strategic functions and problems), Dar al Mareekh, KSA. 